\title{
Analisis Peramalan (Forecasting) Penjualan Jasa Pada Warnet Bulian City di Muara Bulian
}

\author{
Fauziah, Yulia Istia Ningsih, Eva Setiarini \\ STIE-GK Muara Bulian
}

\begin{abstract}
In the business world Forecasting is one of the most important factors that must be applied in a business. Forecasting is a method for estimating a value in the future by using past data effectively and efficiently. This research was conducted at Warnet Bulian City In this study, the author discusses the analysis of forecasting (Forecasting) sales of services at the Bulian City internet cafe in Muara Bulian. Forecasting is done using three methods namely the MOVA (Moving Average) method, the WMA (Weight Moving Average) method and the Exponential Smoothing Method by comparing the smallest error rate Forecasting using the MA (Moving Average) method for 3 periods is predicted the level of profit to be gained by Bulian City Warnet in August amounted to. 11,117,833 with MAD 1,487,370. Forecasting using the Weigh Moving Averages (WMA) 3 method is forecasted at 12,287,300 with MAD Error 3,016,016 while the forecast using the double exponential smoothing method is 13,522,572 with MAD 5513617,364 then the forecasting method chosen is the Single Exponential Smoothing method with the Forecast value in August 2018 9,581.69 for the The Forecast Error is MAD of 1,378,375 which is the method with the smallest error rate.
\end{abstract}

Keywords: Forecasting; Cafe; Moving Average Method; WMA (Weight Moving Average) Method; Exponential Smoothing Method; Error

\section{PENDAHULUAN}

Forecasting (peramalan) adalah salah satu unsur yang sangat penting dalam proses pengambilan keputusan. Peramalan yang dilakukan umumnya didasarkan pada masa lalu yang kemudian dianalisis dengan menggunakan metode atau cara-cara tertentu. Data masa lalu dikumpulkan, dipelajari, dianalisis dan dihubungkan dengan perjalanan waktu, karena adanya faktor waktu tersebut, maka dari data hasil analisis tersebut kita dapat mencoba mengatakan sesuatu yang terjadi di masa yang akan datang.

Dalam hal ini kita dihadapkan pada suatu kondisi ketidak pastian, sehingga akan ada faktor akurasi atau ketidaksamaan yang harus diperhitungkan. Peramalan selalu bertujuan agar ramalan yang di buat biasa meminimumkan kesalahan peramalan (forecast error) artinya perbedaan antara kenyataan dengan ramalan tidak terlalu jauh. Ramalan yang baik adalah ramalan yang mendekati kenyataan. Oleh karena peramalan digunakan sebagi acuan dalam pengambilan keputusan maka ramalan yang baik sangat dibutuhkan. Peranan peramalan menjelajah ke berbagai bidang, seperti ekonomi, keuangan, pemasaran, produksi riset operasional, administrasi negara, meteorology, geofisika dan kependudukan. Karena besarnya peramalan tersebut maka memerlukan kerja yang mendalam mengenai langkah-langkah dalam melakukan peramalan ini. Dengan mengetahui langkah-langkah peramalan yang baik diharapkan dapat diperoleh ramalan yang baik pula. Untuk mencapai ramalan yang baik maka diperlukan model yang tepat atau mempunyai nilai ramalan yang mendekati kebenaran.

Akurasi suatu ramalan berbeda untuk setiap peramalan tergantung pada berbagai faktor yang mempengaruhinya. Hasil suatu ramalan tidak selalu dapat dipastikan kebenarannya dalam hitungan 100\% mutlak, tetapi hal tersebut tidak berarti bahwa peramalan telah banyak digunakan dan membantu dengan baik dalam berbagai manajemen sebagai dasar dalam perencanaan, pengawasan dan pengambilan keputusan. salah satu diantaranya adalah forecasting penjualan produk Jasa Warung Internet.

Penjualan jasa Warnet Bulian City Net mengalami fluktuasi setiap bulannya dapat dilihat pada penjualan bulan Maret April 2018 Rp.8.637.000 sebesar Rp.10.112.500-, Sedangkan bulan Mei 2018 Rp.9.631.500-, berawal dari sinilah peneliti tertarik untuk mengkaji dan melakukan peramalan penjualan jasa pada warung internet Bulian City agar usaha tersebut dapat memperkirakan apa yang akan terjadi pada masa yang akan datang disebut dengan peramalan (FORECAST) agar dapat menentukan tujuan yang akan dicapai oleh usaha itu sendiri.

\section{Tinjauan Pustaka \\ Tekhnik Proyeksi Bisnis}

Tekhnik Proyeksi Bisnis merupakan suatu cara atau pendekatan untuk menentukan ramalan (perkiraan) mengenai sesuatu dimasa yang akan datang. Proyeksi ( Forecast ) menjadi sangat penting karena penyusunan suatu rencana diantaranya didasarkan pada suatu proyeksi atau forecast.

Didalam ilmu-ilmu social segala sesuatu yang akan terjadi dimasa yang akan datang tidak ada yang terjadi secara pasti. Yang terjadi dimasa yang akan datang akan penuh dengan resiko dan ketidak pastian, manajemen perlu melakukan proyeksi atau forecast terutama forecast tentang penjualan. Forecast penjualan tersebut sebagai dasar untuk menentukan recana penjualan.

\section{Penjualan dan Anggaran Penjualan}


Penjualan merupakan suatu usaha terpadu untuk mengembangkan rencana-rencana strategis yang diarahkan pada usaha pemuasan kebutuhan dan keinginan pembeli. Penjualan juga merupakan sumber hidup suatu perusahaan, karena dari penjualan dapat diperoleh laba. Faktor-faktor yang mempengaruhi penjualan yaitu bisa berasal dari internal perusahaan maupun eksternal perusahaan. Anggaran (budget) merupakan suatu rencana yang disusun secara sistematis yang meliputi seluruh kegiatan perusahaan, yang dinyatakan dalam unit (kesatuan) moneter dan berlaku untuk jangka waktu (periode) tertentu yang akan datang (M.Munandar, 2010:1)

Anggaran penjualan (Sales budget) merupakan budget yang merencanakan secara lebih terperinci tentang penjualan perusahaan selama periode yang akan datang, yang didalamnya meliputi rencana tentang jenis (kualitas) barang yang akan dijual, jumlah (kualitas)barang yang akan dijual, harga barang yang akan dijual, waktu penjualan serta tempat (daerah) pejualannya (Lincolin Arsyad, ekonomi manajerial edisi 7 tahun 2009

\section{Peramalan (Forecasting)}

Peramalan (Forecast) adalah seni dan ilmu untuk memperkirakan kejadian dimsa depan. Hal ini dapat dilakukan dengan melibatkan pengambilan data masalalu baik beberapa bulan terakhir maupun beberapa tahun terakhir dan menempatkannya ke masa yang akan datang dengan suatu bentuk model matematis.

Peramalan penjualan memberikan titik awal untuk asumsi yang digunakan dalam kegiatan perencanaan dan untuk pengembangan sistem kontrol keuangan jangka pendek. Tingkat produksi perusahaan terkait erat dengan output penjualannya. Anggaran keuangan, oleh karena itu, tergantung pada perkiraan penjualan untuk angka pendapatan diproyeksikan.

Peramalan adalah suatu usaha untuk meramalkan keadaan di masa mendatang melalui pengujian keadaan dimasa lalu. Esensi peramalan adalah perkiraan peristiwa-peristiwa diwaktu yang akan datang atas dasar pola-pola di waktu yang lalu dan penggunaan kebijakan terhadap proyeksi-proyeksi dengan pola-pola dibawah waktu yang lalu. Permalan memerlukan kebijakan, sedangkan proyeksi-proyeksi adalah fungsi-fungsi mekanikal.

Ada 3 unsur pokok yang sama dalam kaitannya dengan masalah peramalan yaitu : Pertama adalah waktu. Secara spesifik dalam semua situasi pengambilan keputusan selalu berhubungan dengan masa depan. Kedua adalah situasi ketidakpastian. Terakhir adalah bahwa keputusan-keputusan yang didasarkan pada ramalan-ramalan yang dibuat berdasarkan analisis statistik untuk mengidentifikasi pola dan data historis yang daoat diramalkan.
Ada lima prinsip peramalan yang sangat perlu diperhatikan untuk mendapatkan hasil peramalan yang baik, yaitu:

1. Peramalan selalu mengandung error. Peramalan mengurangi faktor ketidakpastian tetapi tidak pernah mampu untuk menghilangkannya.

2. Peramalan harus mencakup ukuran dari error. Besarnya error dapat dijelaskan dalam bentuk kisaran sekitar hasil peramalan baik dalam unit atau persentase dan probabilitas tentang permintaan sesungguhnya akan berada dalam kisaran tersebut.

3. Peramalan item yang dikelompokkan dalam famili selalu lebih akurat dibandingkan dengan peramalan dalam item per item.

4. Peramalan untuk jangka pendek selalu lebih akurat dibandingkan dengan peramalan untuk jangka panjang. Dalam waktu jangka pendek. Kondisi yang mempengaruhi permintaan cenderung tetap/berubah lamban sehingga permalan jangka pendek cenderung lebih akurat.

5. Apabila dimungkinkan, perkiraan besarnya permintaan lebih disukai berdasarkan perhitungan dari pada hasil peramalan.

\section{Jenis-jenis Metode Peramalan}

Metode peramalan penjualan (forecasting) menurut sifatnya dapat dibedakan menjadi dua yaitu:

\section{Bersifat Kualitatif ( Non Statistical Method atau Opinion Method)}

Merupakan cara peramalan atau forecasting yang didasarkan pada masa lampau, data saat ini, target yang ingin dicapai, berdasarkan intuisi dan pengalaman serta pendapat seseorang misalnya:
a. Pendapat pimpinan bagian penjualan
b. Pendapat para petugas/staf penjualan
c. Pendapat lembaga-lembaga penyalur
d. Pendapat ahli
e. Pendapat para konsumen

\section{Bersifat Kuantitatif ( Statistical Method)}

Dengan menggunakan cara peramalan (forecasting) secara kuantitatif diharapkan dapat sejauh mungkin menghilangkan unsur-unsur subjektif atau pendapat pribadi, sehingga hasil taksirannya lebih akurat dan dapat dipertanggung jawabkan, serta dapat lebih berguna sebagai dasar pengambilan keputusan-keputusan perusahaan. Dengan kata lain cara peramalan (forecasting) yang bersifat kuantitatif ini dapat dipakai sebagai cara permalan yang pokok (utama). Sedangkan cara permalan yang bersifat kualitatif dipakai sebagai pelengkapnya (penunjang).

\section{Metode Trend Setengah Rata-rata (Semi-average Method )}

Metode Trend Setengah Rata-rata adalah metode peramalan yang mengelompokan data menjadi dua kelompok. Metode ini sudah menggunakan perhitungan-perhitungan dari data 
statistic sehingga unsur-unsur subjektifitas sudah dihilangkan. Prosedurnya sebagai berikut :

a. Data yang ada dibagi menjadi dua kelompok dengan jumlah sama

b. Tahun dasar ada pada tengah-tengah kelompok 1

c. Pada masing-masing kelompok ditentukan nilai $\mathrm{X}$, semi total dan semi average

d. Jumlah nilai $\mathrm{X}$ pada kelompok 1 harus 0

e. Proyaksi ( forecast) ditahun yang akan datang tergantung berapa besar nilai $\mathrm{X}$.

Nilai trend dihitung dengan formula $\mathrm{Y}=\mathrm{a}+\mathrm{B}$

\section{a. Metode Trend Moment}

Trend Moment adalah perhitungan peramalan yang dimana tahun dasarnya ditentukan pada data paling awal. Metode ini hamper sama dengan metode least square.

b. Metode Trend Least Square ( Least Square Method )

Metode ini adalah cara perhitungan dengan variable $\mathrm{x}$ harus diangka ganjil. Metode ini merupakan penyederhanaan dari metode Trend Moment. Sehingga akan mempermudah dalam perhitungannya.

c. Metode Trend Kuadratik ( Parabolic Method)

Trend kuadratik adalah trend yang nilai variabel naik atau turun secara linier atau terjadinya parabola bila datanya dibuat scatter plot (hubungan variabel dependen dan independen adalah kuadratik)

\section{d. Trend Exponential}

Selain trend diatas ada satu lagi trend yang biasa digunakan oleh seorang peramlan, yaitu Trend Exponential untuk mengetahui apakah suatu data tepat diproyeksi dengan Trend Exponential, yaitu apabila nilai logaritma dari dta yang ada perubahannya relatif sama.

\section{Pengukuran Hasil Akurasi Peramalan}

Merurut literature buku Sofyan Assauri, nilai error yang mendekati akurat yaitu yang memiliki nilai < 1 Forecast sangat penting sebagai pedoman dalam pembuatan rencana. Kerja dengan menggunakan forecast akan jauh lebih baik dibandingkan tanpa forecast sama sekali. Salah satu cara mengevaluasi tehnik permalan adalah menggunakan ukuran tentang tingkat perbedaan antara hasil peramalan dengan permintaan yang sebenarnya terjadi, menurut Nasution (2011). Ada empat ukuran yang biasa digunakan, yaitu :

\section{a. Rata-rata Deviasi Mutlak (Mean Absolute} Deviation = MAD)

MAD merupakan rata-rata kesalahan mutlak selama perode tententu tanpa memperhatikan apakah hasil peramalan lebih besar atau lebih kecil dibandingkan kenyataannya.

b. Rata-rata kuadrat kesalahan ( Mean Square Error )

MSE merupakan metode alternatif dalam suatu metode peramalan. Pendekatan ini penting karena teknik ini menghasilkan kesalahan yang sangat bear. MSE dihitung dengan menjumlahkan kuadrat semua kesalahan peramalan pada setiap periode dan membaginya dengan jumlah periode peramalan.

c. Rata-rata Kesalahan Permalan (Mean Forecast Error = MFE )

MFE sangat efektif untuk mengetahui apakah suatu hasil peramalan selama periode tertentu terlalu tinggi atau terlalu rendah, nol. MFE dihitung dengan menjumlahkan semua kesalahan peramalan selama periode peramalan dan membaginya dengan jumlah periode peramalan.

d. Rata-rata Persentase Kesalahan Absolute (Mean Absolute Percentage Error = MAPE )

MAPE merupakan ukuran kesalahan relatif dan menyatakan persentase kesalahan hasil peramalan terhadap permintaan aktual selama periode tertentu yang akan memberikan informasi persentase kesalahan terlalu tinggi atau terlalu rendah.

\section{HASIL DAN PEMBAHASAN \\ Perkembangan Volume Penjualan Jasa pada Warnet Bulian City di Muara Bulian}

Sejak berdiri dari tahun 2008 pemilik usaha Warnet Bulian City tidak pernah membuat peramalan penjualan sehingga tidak didapat data perkiraan peramalan penjualan dimasa yang akan datang, maka sulit membuat perencanaan untuk pengembangan usaha. Dibawah ini penulis memperlihatkan perkembangan volume penjualan jasa pada bulan Agustus 2017 hingga bulan Juli 2018

Tabel 1. Perkembangan Volume Penjualan Jasa pada Warnet Bulian City di Muara Bulian Agustus 2017-Juli 2018

\begin{tabular}{clrr}
\hline Periode & \multicolumn{1}{c}{ Bulan } & Penjualan (Rp) & Perkembangan (\%) \\
\hline 1 & Agustus 2017 & $9,875,000$ & 0 \\
2 & September 2017 & $9,480,500$ & $-3.99 \%$ \\
3 & Oktober 2017 & $10,263,000$ & $8.25 \%$ \\
4 & November 2017 & $8,952,500$ & $-12.76 \%$ \\
5 & Desember 2017 & $8,371,500$ & $-6.48 \%$ \\
6 & Januari 2018 & $9,750,500$ & $16.47 \%$ \\
7 & Februari 2018 & $9,348,500$ & $-4.12 \%$ \\
8 & Maret 2018 & $8,637,000$ & $-7.61 \%$ \\
9 & April 2018 & $10,112,500$ & $17.08 \%$
\end{tabular}




$\begin{array}{llrr}10 & \text { Mei } 2018 & 9,631,500 & -4.75 \% \\ 11 & \text { Juni } 2018 & 7,500,000 & -22.13 \% \\ 12 & \text { Juli } 2018 & 16,222,000 & 116 \% \\ & \text { JUMLAH } & 118,144,500 & \end{array}$

\section{Sumber Data: Warnet Bulian City}

Dari tabel perkembangan volume penjualan tersebut dapat dilihat terjadi penurunan terbesar pada bulan Juni 2018 yaitu turun sebesar $22.13 \%$ hal ini disebabkan karena adanya libur puasa Ramadhan dan hari raya idul fitri sedangkan peningkatan terbesar terjadi pada bulan Juli 2018 yaitu naik sebesar $116 \%$ hal ini di sebabkan karena para siswa dan siswi sudah kembali bersekolah, begitu pula dengan mahasiswa dan mahasiswi sudah kembali beraktifitas dari masa libur di bulan Juni 2018 tersebut.

\section{Ramalan Penjualan Jasa Pada Warnet Bulian City di Muara Bulian}

Untuk mengetahui peramalan penjualan jasa diperlukan data yang cukup relevan, adapun data yang digunakan untuk meramalkan penjualan jasa pada Warnet Bulian City di Muara Bulian dapat dilihat dari table 2 dibawah ini.

Tabel 2. Data Penjualan Jasa pada Warnet Bulian City di Muara Bulian Agustus 2017-Juli 2018

\begin{tabular}{clr}
\hline Periode & \multicolumn{1}{c}{ Bulan } & Penjualan (Rp) \\
\hline 1 & Agustus 2017 & $9,875,000$ \\
2 & September 2017 & $9,480,500$ \\
3 & Oktober 2017 & $10,263,000$ \\
4 & November 2017 & $8,952,500$ \\
5 & Desember 2017 & $8,371,500$ \\
6 & Januari 2018 & $9,750,500$ \\
7 & Februari 2018 & $9,348,500$ \\
8 & Maret 2018 & $8,637,000$ \\
9 & April 2018 & $10,112,500$ \\
10 & Mei 2018 & $9,631,500$ \\
11 & Juni 2018 & $7,500,000$ \\
12 & Juli 2018 & $16,222,000$ \\
& \multicolumn{1}{c}{ JUMLAH } & $118,144,500$ \\
\hline
\end{tabular}

Sumber Data: Warnet Bulian City

\section{Metode MOVA (Moving Average)}

Moving Averages ( rata-rata bergerak ) yaitu melakukan peramalan dengan mengambil sekelompok nilai pengamatan, mencari rata-ratanya, lalu mengambil rata-rata tersebut sebagai peramalan untuk periode berikutnya. Istilah rata-rata bergerak digunakan, karena setiap data observasi baru tersedia, maka angka rata-rata yang baru dihitung dan digunakan sebagai ramalan. Untuk mengetahui peramalan penjualan jasa pada Warnet Bulian City dengan menggunakan Metode MOVA ( Moving Average ) adalah sebagai berikut :

$\mathrm{MA}=\Sigma$ Penjualan nyata pada $\mathrm{n}$ periode

$\Sigma$ Periode (n) yang digunakan dalam moving average

Tabel 3. Peramalan dengan Metode MOVA (Moving Average) dengan perata 3 bulan

\begin{tabular}{lcccc}
\hline \multicolumn{1}{c}{ BULAN } & PENJUALAN (RP) & PERAMALAN $(\mathbf{F t})(\mathbf{R P})$ & ERROR (RP) & ABS ERROR (RP) \\
\hline Agustus 2017 & $9,875,500$ & - & - & - \\
September 2017 & $9,480,500$ & - & - & - \\
Oktober 2017 & $10,263,000$ & - & - & - \\
Noveber 2017 & $8,952,500$ & $9,873,000$ & $-920,500$ & 920,500 \\
Desember 2017 & $8,371,500$ & $9,565,333$ & $-1,193,833$ & $1,193,833$ \\
Januari 2018 & $9,750,500$ & $9,195,667$ & 554,833 & 554,833 \\
Februari 2018 & $9,348,500$ & $9,024,833$ & 323,667 & 323,667 \\
Maret 2018 & $8,637,000$ & $9,156,833$ & $-519,833$ & 159,833 \\
April 2018 & $10,112,500$ & $9,245,333$ & 867,167 & 867,167 \\
Mei 2018 & $9,631,500$ & $9,366,000$ & 265,500 & 265,500 \\
Juni 2018 & $7,500,000$ & $9,460,333$ & $-1,960,333$ & $1,960,333$ \\
Juli 2018 & $16,222,000$ & $9,081,333$ & $7,140,667$ & $7,140,667$ \\
Agustus 2018 & - & $11,117,833$ & $11,117,833$ & $11,117,833$ \\
& TOTAL & & & \\
\hline
\end{tabular}


Jadi jika menggunakan metode MOVA ( Moving Average) 3 periode diramalkan pendapatan atau tingkat keuntungan yang akan didapatkan oleh Warnet Bulian City pada bulan Agustus 2018 sebesar Rp. 11,117,833,-dengan kisaran pendapatan bersih yaitu Rp.9,630,463.sampai Rp. 12,605,203,-

\section{Weigh Moving Averages (WMA)}

Metode Peramalan Weigh Moving Averages (WMA) Apabila ada pola yang trend dan pola yang terditeksi, bobot dapat digunakan untuk menempatkan penekanan yang lebih pada nilai terkini. Untuk mengetahui peramalan penjualan jasa pada Warnet Bulian City dengan menggunakan Metode Weigh Moving Averages (WMA) 3 bulan dengan bobot 3, 2, dan 1 adalah sebagai berikut :

Rumus :

$\mathrm{MA}=\underline{\Sigma(\text { Bobot periode } \mathrm{n})(\text { penjualan pada periode } \mathrm{n})}$

Tabel 4. Peramalan dengan Metode WMA ( 3 ) bobot 3, 2, dan 1

\begin{tabular}{clrrrr}
\hline PERIODE & \multicolumn{1}{c}{ BULAN } & PENJUALAN (RP) & PERAMALAN (Ft) (RP) & ERROR (RP) & ABS ERROR (RP) \\
\hline 1 & Agustus 2017 & $9,875,500$ & - & & - \\
2 & September 2017 & $9,480,500$ & - & - & - \\
3 & Oktober 2017 & $10,263,000$ & - & - & - \\
4 & Noveber 2017 & $8,952,500$ & $9,937,583$ & $-985,083$ & $-985,083$ \\
5 & Desember 2017 & $8,371,500$ & $9,477,333$ & $-1,105,833$ & $-1,105,833$ \\
6 & Januari 2018 & $9,750,500$ & $8,880,417$ & 870,083 & 870,083 \\
7 & Februari 2018 & $9,348,500$ & $6,646,383$ & $2,702,117$ & $2,702,117$ \\
8 & Maret 2018 & $8,637,000$ & $9,319,667$ & $-682,667$ & $-682,667$ \\
9 & April 2018 & $10,112,500$ & $9,060,666$ & $1,051,834$ & $1,051,834$ \\
10 & Mei 2018 & $9,631,500$ & $9,493,500$ & 138,000 & 138,000 \\
11 & Juni 2018 & $7,500,000$ & $9,626,083$ & $-2,126,083$ & $-2,126,083$ \\
12 & Juli 2018 & $16,222,000$ & $8,645,917$ & $7,576,083$ & $7,576,083$ \\
& Agustus 2018 & - & $12,216,250$ & $12,216,250$ & $12,216,250$ \\
& TOTAL & - & & & $\mathbf{2 9 , 4 5 4 , 0 3 3}$ \\
\hline
\end{tabular}

Sumber : Data Diolah

Jadi jika menggunakan metode Weigh Moving Averages (WMA) 3 periode diramalkan pendapatan atau tingkat keuntungan yang akan didapatkan oleh Warnet Bulian City pada bulan Agustus 2018 sebesar Rp. $12,216,250$,- dengan kisaran pendapatan bersih yaitu Rp.8,943,580.- sampai Rp. 15,488,920,-

\section{Metode Exponential Smoothing \\ Single Exponential Smoothing dengan a 0,1}

Exponential Smoothing dengan $\alpha 0.1$ artinya memberi bobot yang lebih kecil pada peramalan sebelumnya disbanding dengan data sebelumnya.

Tabel 5. Perhitungan Peramalan Penjualan Jasa Warnet Bulian City dengan Metode Single Exponential Smoothing

\begin{tabular}{lrrrrr}
\hline \multicolumn{1}{c}{ BULAN } & PENJUALAN & \multicolumn{1}{c}{ FORECAST } & \multicolumn{1}{c}{ ERROR } & \multicolumn{1}{c}{ AD } & \multicolumn{1}{c}{ SE } \\
\hline Agustus 2017 & $9,875,500$ & & & & \\
September 2017 & $9,480,500$ & $9,875,500$ & 1.00 & 1.00 & 1.00 \\
Oktober 2017 & $10,263,000$ & $9,836,000$ & 427,000 & 427,000 & $182,329,000,000$ \\
November 2017 & $8,952,500$ & $9,878,700$ & $-926,700$ & 926,700 & $858,772,890,000$ \\
Desember 2017 & $8,371,500$ & $9,786,080$ & $-1,414,580$ & $1,414,580$ & $2,001,036,576,400$ \\
Januari 2018 & $9,750,500$ & $9,644,622$ & 105,878 & 105,878 & $11,210,150,884$ \\
Februari 2018 & $9,348,500$ & $9,655,210$ & $-306,710$ & 306,710 & $94,071,024,100$ \\
Maret 2018 & $8,637,000$ & $9,624,539$ & $-987,539$ & 987,539 & $975,233,276,521$ \\
April 2018 & $10,112,500$ & $9,525,785$ & 586,715 & 586,715 & $344,234,491,225$ \\
Mei 2018 & $9,631,500$ & $9,584,457$ & 47,043 & 47,043 & $2,213,043,849$ \\
Juni 2018 & $7,500,000$ & $9,589,161$ & $-2,089,161$ & $2,089,161$ & $4,364,593,683,921$ \\
Juli 2018 & $16,222,000$ & $9,380,245$ & $6,841,755$ & $6,841,755$ & $46,809,611,480,025$ \\
JUMLAH & & & $2,283,702$ & $13,733,082$ & $55,643,305,616,925$ \\
Ramalan Bulan Agustus 2018 & & $\mathbf{1 0 , 0 6 4 , 4 2 1}$ & Mean & $\mathbf{1 , 2 4 8 , 4 6 2}$ & $\mathbf{5 , 0 5 8 , 4 8 2 , 3 2 8 , 8 1 1}$ \\
\hline
\end{tabular}

Sumber : Data Diolah

Untuk mengukur tingkat kesalahan dalam peramalan menggunakan MAD dengan rumus sebagai berikut: 
Atau $\frac{\sum|D t-F t|}{n}$

Mean Absolute Error : $\underline{13,733,082}$

$$
11
$$

$$
=1,248,462
$$

Mean Absolute Error : $\underline{55,643,305,616,925}$

$$
11
$$$$
=5,058,482,328,811
$$

\section{Forecast Agustus 2018 $=$ Rp. 10.064.421}

Untuk Forecast Errornya adalah sebagai berikut:

$\mathrm{MAD}=\mathbf{1 , 2 4 8 , 4 6 2}$

$$
\mathrm{MSE}=\mathbf{5 , 0 5 8 , 4 8 2 , 3 2 8 , 8 1 1}
$$

\section{Double Exponential Smoothing dengan a 0,1}

Exponential Smoothing dengan $\alpha \quad 0,1$ artinya memberi bobot yang sama antara peramalan sebelumnya sehingga terjadi keseimbangan.

Tabel 6. Perhitungan Peramalan Penjualan Jasa Warnet Bulian City dengan Metode Double Exponential Smoothing dengan $\alpha 0.1$

\begin{tabular}{crrrccc}
\hline Bulan Ke & Penjualan & \multicolumn{1}{c}{ S' $^{\prime}$} & \multicolumn{1}{c}{ S" $^{\prime \prime}$} & at & bt & Forecast (m) \\
\hline 1 & 9.875 .000 & 9.875 .500 & 9.875 .500 & - & - & - \\
2 & 9.480 .500 & 9.836 .000 & 1.875 .550 & 17.796 .450 & 884.494 & 9.875 .500 \\
3 & 10.263 .000 & 9.878 .700 & 2.675 .865 & 17.081 .535 & 799.982 & 18.680 .944 \\
4 & 8.952 .000 & 9.786 .080 & 3.386 .887 & 16.185 .273 & 911.021 & 17.881 .517 \\
5 & 8.371 .500 & 9.644 .622 & 4.012 .661 & 15.276 .583 & 625.773 & 16.896 .294 \\
6 & 9.750 .500 & 9.655 .210 & 4.576 .916 & 14.733 .504 & 564.255 & 15.902 .356 \\
7 & 9.348 .500 & 9.624 .539 & 5.081 .678 & 14.167 .400 & 504.762 & 14.169 .249 \\
8 & 8.637 .000 & 9.525 .785 & 5.526 .089 & 13.525 .481 & 444.411 & 14.672 .162 \\
9 & 10.112 .500 & 9.584 .456 & 5.931 .926 & 13.236 .986 & 405.837 & 13.969 .892 \\
10 & 9.631 .500 & 9.589 .160 & 6.297 .649 & 12.880 .671 & 365.723 & 13.642 .823 \\
11 & 7.500 .000 & 9.380 .244 & 6.605 .908 & 12.154 .580 & 308.260 & 13.246 .394 \\
12 & 16.222 .000 & 10.064 .420 & 6.951 .759 & 13.176 .721 & 345.851 & 12.462 .840 \\
\hline
\end{tabular}

Sumber Data : Penjualan Jasa Warnet Bulian City

Adapun hasil ramalan bulan Agustus 2018 adalah sebagai Forecast Agustus $2018=\mathbf{R p}$. 13.522.572

Tabel 7. Perhitungan Forecast Error

\begin{tabular}{crrrrr}
\hline Bulan Ke & Penjualan & Forecast $(\mathbf{m})$ & error & Absulute & \multicolumn{1}{c}{ Squared } \\
\hline 1 & 9.875 .000 & - & - & - & \\
2 & 9.480 .000 & 9.875 .500 & 395.500 & 395.500 & 395.500 \\
3 & 10.263 .000 & 18.680 .944 & 8.417 .944 & 8.417 .944 & 70.861 .781 .187 .136 \\
4 & 8.952 .000 & 17.881 .517 & 8.929 .517 & 8.929 .517 & 79.736 .273 .853 .289 \\
5 & 8.371 .500 & 16.896 .294 & 8.524 .794 & 8.524 .794 & 72.672 .112 .742 .436 \\
6 & 9.750 .500 & 15.902 .356 & 6.151 .856 & 6.151 .856 & 37.845 .332 .244 .736 \\
7 & 9.348 .500 & 14.169 .249 & 4.820 .749 & 4.820 .749 & 23.239 .620 .921 .001 \\
8 & 8.637 .000 & 14.672 .162 & 5.025 .638 & 5.025 .638 & 25.257 .037 .307 .044 \\
9 & 10.112 .500 & 13.969 .892 & 3.857 .392 & 3.857 .392 & 14.879 .473 .041 .664 \\
10 & 9.631 .500 & 13.642 .823 & 4.011 .323 & 4.011 .323 & 16.090 .712 .210 .329 \\
11 & 7.500 .000 & 13.246 .394 & 5.746 .394 & 5.746 .394 & 33.021 .044 .003 .236 \\
12 & 16.222 .000 & 12.462 .840 & 3.759 .160 & 3.759 .160 & 14.131 .283 .905 .600 \\
& TOTAL & & & $60,649,791$ & $398,900,814,871,171$ \\
\hline
\end{tabular}

Sumber : Data Diolah

Untuk mengukur tingkat kesalahan dalam peramalan menggunakan MAD dengan rumus sebagai berikut :

$$
\mathrm{MAD}=\frac{\sum \text { (absolut dari forecast errors) }}{\mathrm{n}}
$$

$$
\begin{aligned}
& \frac{\sum|D t-F t|}{n} \\
& \text { Atau } \\
& \text { MAD }=\frac{60,649,791}{11}
\end{aligned}
$$

$$
=5513617.364
$$

Metode Peramalan Yang Paling Tepat Untuk Menentukan Penjualan Jasa pada Warnet Bulian City di Periode yang akan Datang

Dari perhitungan ke 3 metode diatas, diketahui bahwa hasil perhitungan dengan memakai metode Single Exponential Smoothing hasil peramalan yang didapat lebih cocok diterapkan pada usaha Warnet Bulian City dalam meramalkan penjualan Jasa pada bulan Agustus karena metode Single Exponential Smoothing memiliki 
tingkat kesalahan yang lebih kecil/rendah dibandingkan dengan Metode MOVA (Moving Average), Metode WMA (Weight Moving Average) dan Metode Double Exponential Smoothing
Adapun tingkat kesalahan peramalan MAD (Mean Absolut Error) dapat dilihat pada tabel dibawah ini :

Tabel 8. Perbandingan Forecast dan Error (MAD)

\begin{abstract}
Metode
Metode MOVA (Moving Average)

Metode WMA (Weight Moving Average)

Metode Single Exponential Smoothing

Metode Double Exponential Smoothing
\end{abstract}

Dari tabel diatas terlihat metode MOVA (Moving Average) peramalan (forecast) sebesar 11,117,833 dengan error 1,487,370, metode Metode WMA (Weight Moving Average) yaitu peramalan (forecast) sebesar 12,287,300 dengan tingkat Error 3,016,016 Sedangkan Metode Single Exponential Smoothing yaitu peramalan (forecast) sebesar 9,581,697 dengan error 1,378,375 dan Metode Double Exponential Smoothing yaitu peramalan (forecast) sebesar 13.522.572 dengan error 5,513,617

Jadi tingkat kesalahan (error) terkecil adalah dengan memakai metode Single Exponential Smooting, metode ini bisa dijadikan metode untuk menghitung peramalan penjualan jasa Warnet Bulian City pada bulan Agustus 2018

\section{SIMPULAN}

Berdasarkan analisis dan pembahasan yang telah penulis lakukan, maka penulis menyimpulkan bahwa :

1. Penjualan Jasa pada Warnet Bulian City mengalami fluktuasi.

2. Forecast Volume penjualan Jasa pada Warnet Bulian City di Muara bulian pada Bulan Agustus 2018

a. Metode MA (Moving Average) 3 periode forecast hasil penjualan Warnet Bulian City pada bulan Agustus sebesar Rp. 11,117,833,- dengan MAD sebesar 1,487,370

b. Metode Weigh Moving Averages (WMA) 3 periode forecast hasil penjualan Warnet Bulian City pada bulan Agustus 2018 sebesar Rp. 12,216,250,- dengan MAD sebesar 3,272,670

c. Metode Single Exponential Smoothing dengan $\alpha$ 0.01 forecast hasil penjualan Warnet Bulian City pada bulan Agustus 2018 adalah sebesar Rp. 10.064.421 dengan MAD sebesar 1,248,462

d. Metode Double Exponential Smoothing forecast hasil penjualan Warnet Bulian City pada bulan Agustus 2018 adalah Rp. 13.522.572 dengan MAD 5513617.364

3. Metode Single Exponential Smoothing adalah metode yang lebih cocok diterapkan pada usaha Warnet Bulian City dalam meramalkan penjualan Jasa pada bulan Agustus karena metode Single Exponential Smoothing memiliki tingkat kesalahan yang lebih $\mathrm{kecil} / \mathrm{rendah}$.
Forecast

$11,117,833$

$12,216,250$

10.064 .421

13.522 .572
Error

$1,487,370$

$3,272,670$

$1,248,462$

$5,513,617$

\section{DAFTAR PUSTAKA}

Aritonang R, Lebrin R.(2009). Peramalan Bisnis, Edisi Kedua. Bogor : CHALIA INDONESIA

Arsyad Lincolin.(2001). Peramalan Bisnis, Edisi Petama. Yogyakarta : BPFE

Barry, Render dan Jay Heizer. 2001. Prinsip-prinsip Manajemen Operasi: Operations Management. Jakarta : Salemba Empat.

Gunawan Adisaputro dan Yunita Anggraini. (2017). Anggaran Bisnis Analisis, Perencanaan, dan Pengendalian Laba. Yogyakarta : UPP STIM YKPN

Gaspersz, Vincent,2005. Total Quality Management. PT Gramedia Pustaka Utama, Jakarta.

Heizer Jay, Render Barry. 2005. Operations Management. Jakarta: Salemba Empat.

Indriyo Gitisudarmo dan Mohammad Naj Mudin. (2001), Teknik Proyeksi Bisnis. Yogyakarta : BPFE

Munandar, M. 2010. Budgeting Perencanaan Kerja Pengkoordinasian Kerja Pengawasan Kerja. Yogyakarta: BPFE.

Nasution. 2011. Metode Research Penelitian Ilmiah. Jakarta: PT Bumi Aksara.

Shinta, Lusi Wardani. 2011. Teknik Proyeksi Untuk Bisnis Dan Ekonomi. Yogyakarta: BPFE 